\title{
Management of hepatic artery aneurysm: A case series
}

\author{
Ashley Rosenberg ${ }^{1}$, Katarzyna Trebska-McGowan ${ }^{1}$, Trevor Reichman ${ }^{1}$, \\ Amit Sharma ${ }^{1}$, Adrian Cotterell ${ }^{1}$, Brian Strife ${ }^{2}$, Aamir A. Khan ${ }^{1}$, Vinay Kumaran ${ }^{1}$, \\ David A. Bruno ${ }^{1}$, Marlon F. Levy ${ }^{1}$, and Chandra Shekhar Bhati ${ }^{1}$
}

Departments of ${ }^{1}$ Surgery and ${ }^{2}$ Radiology, Virginia Commonwealth University Health System, Richmond, VA, USA

\begin{abstract}
Hepatic artery aneurysms are rare, but their diagnosis is important because of high mortality and complications. Common risk factors for developing these aneurysms include hypertension, vascular disease, pancreatitis, diabetes, tobacco use, autoimmune diseases, and previous transplantation. Frequent imaging for trauma and tumor surveillance has increased the incidence of naive hepatic aneurysms. These aneurysms can be difficult to manage, and it can be challenging to decide the correct treatment modality for the patient. Hereby, we present four cases of hepatic artery aneurysm and discuss various treatment options. Patient 1 suffered from a proper and right hepatic artery aneurysm discovered incidentally; repaired with an endovascular intervention later complicated by an endoleak which was further managed by another stenting. Patient 2 had a common hepatic artery aneurysm followed with serial imaging without any intervention. Patient 3 had a hepatic artery aneurysm and liver mass diagnosed concurrently. The patient underwent an open surgical repair of his aneurysm with graft and liver resection which was complicated later with rupture of aneurysm followed by surgical bypass repair. Patient 4 suffered from a large hepatic artery aneurysm causing bile duct compression. Her aneurysm was repaired open with splenic artery grafting. Patients were managed from careful observation to surgery with different outcomes. (Ann Hepatobiliary Pancreat Surg 2020;24:333-338)
\end{abstract}

Key Words: Hepatic artery aneurysm; Liver transplantation; Vascular diseases; Angiogram

\section{INTRODUCTION}

Hepatic artery aneurysms are rare visceral aneurysms. ${ }^{1}$ In the past they were associated with high mortality and most of them were discovered at autopsy. ${ }^{2}$ With the increasing use of cross-sectional imaging, they are diagnosed earlier, often before patients become symptomatic. ${ }^{3}$ Historically, surgery was a most utilized approach, depending on the patient's overall health condition and comorbidities. Recently, with the evolution of interventional radiology, most visceral aneurysms are treated by angiography followed by stenting. ${ }^{4}$ Here, we present series of four unique cases of hepatic artery aneurysms and discuss their treatment strategies and decision-making processes for each of them (Table 1).

\section{CASE}

Patient 1 was a 49-year-old man who was diagnosed with a fusiform aneurysmal dilatation of the proper and right hepatic arteries on an axial imaging obtained during work-up for kidney transplant. He did not have any symptoms. Upon diagnosis, the maximal diameter of the aneurysm was $2.9 \mathrm{~cm}$ and interval imaging 5 months later demonstrated an increase in size to $3.3 \mathrm{~cm}$ (Fig. 1). The patient underwent successful celiac and hepatic arteriography through right iliofemoral approach with placement of a covered stent in the hepatic artery aneurysm. Two months after the procedure he represented with abdominal pain and was found to have an endoleak at the distal end of the previously placed stent. He underwent repeat angiography with successful repair of the endoleak with another stent and remains stable and asymptomatic five

Received: January 29, 2020; Revised: June 16, 2020; Accepted: July 9, 2020

Corresponding author: Chandra Shekhar Bhati

Department of Surgery, Virginia Commonwealth University Hospital System, West Hospital, 1200 East Broad Street, Richmond, VA 23298, USA Tel: +18048289314, Fax: +18048282462, E-mail: chandra.bhati@vcuhealth.org

Copyright (C) 2020 by The Korean Association of Hepato-Biliary-Pancreatic Surgery

This is an Open Access article distributed under the terms of the Creative Commons Attribution Non-Commercial License (http://creativecommons.org/ licenses/by-nc/4.0) which permits unrestricted non-commercial use, distribution, and reproduction in any medium, provided the original work is properly cited. Annals of Hepato-Biliary-Pancreatic Surgery • pISSN: 2508-5778 - eISSN: 2508-5859 
Table 1. Patient demographics

\begin{tabular}{|c|c|c|c|c|c|c|c|}
\hline Patient ID & $\begin{array}{c}\text { Sex } \\
(\mathrm{M} \text { or } \mathrm{F})\end{array}$ & Age & Presentation & Treatment & $\begin{array}{l}\text { Cause of } \\
\text { aneurysm }\end{array}$ & Outcome & $\begin{array}{l}\text { Follow up } \# \text { of } \\
\text { months }\end{array}$ \\
\hline Patient 1 & M & 49 & Incidental finding & $\begin{array}{l}\text { Intravascular } \\
\text { stenting }\end{array}$ & Vascular disease & $\begin{array}{l}\text { Endoleak with } \\
\text { repair }\end{array}$ & 57 months \\
\hline Patient 2 & M & 69 & Incidental finding & Observation & Vascular disease & Stable aneurysm & 9 months \\
\hline Patient 3 & M & 41 & Abdominal pain & $\begin{array}{l}\text { Reconstruction } \\
\text { with cadaveric } \\
\text { vein graft }\end{array}$ & $\begin{array}{l}\text { Vascular disease/ } \\
\text { tobacco use }\end{array}$ & $\begin{array}{l}\text { Duodeno-hepatic } \\
\text { aneurysm } \\
\text { fistula }\end{array}$ & 31 months \\
\hline Patient 4 & $\mathrm{~F}$ & 56 & $\begin{array}{l}\text { Abdominal pain/ } \\
\text { obstructive } \\
\text { jaundice }\end{array}$ & $\begin{array}{l}\text { Reconstruction } \\
\text { with splenic } \\
\text { artery bypass }\end{array}$ & Pancreatitis & Transferred care & 3 months \\
\hline
\end{tabular}

Demographic profile of patients and causes with follow up
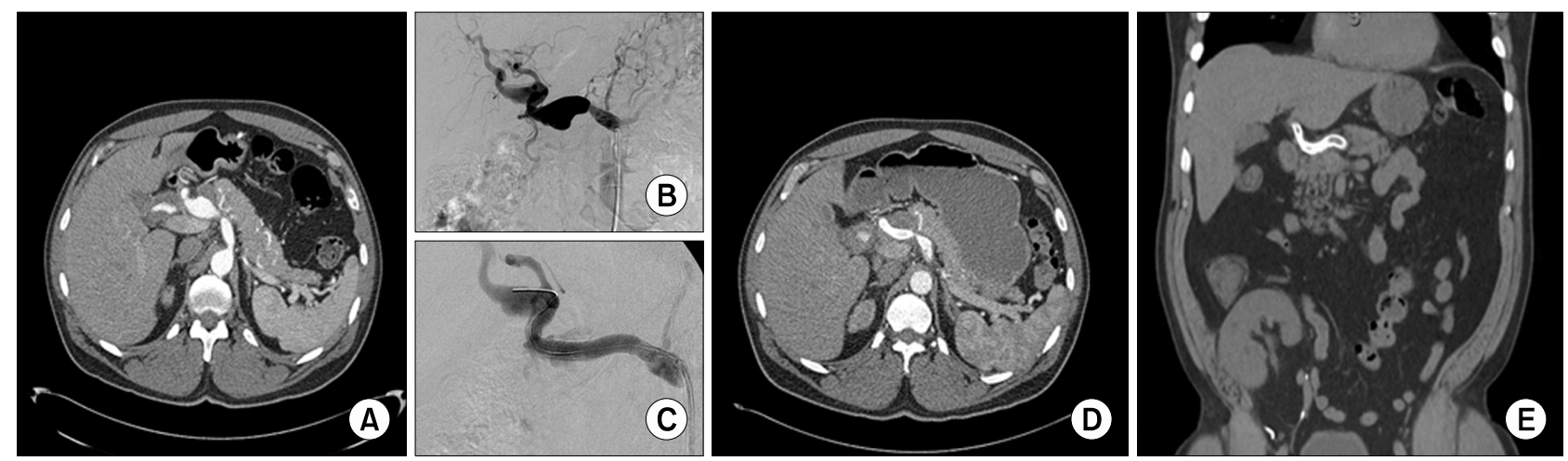

Fig. 1. Patient 1: (A) Pretreatment imaging with fusiform dilatation of hepatic artery; (B, C) angiography procedure with clear fusiform dilation and intraluminal guidewire; (D, E) post-procedure imaging showing resolution of the aneurysm.
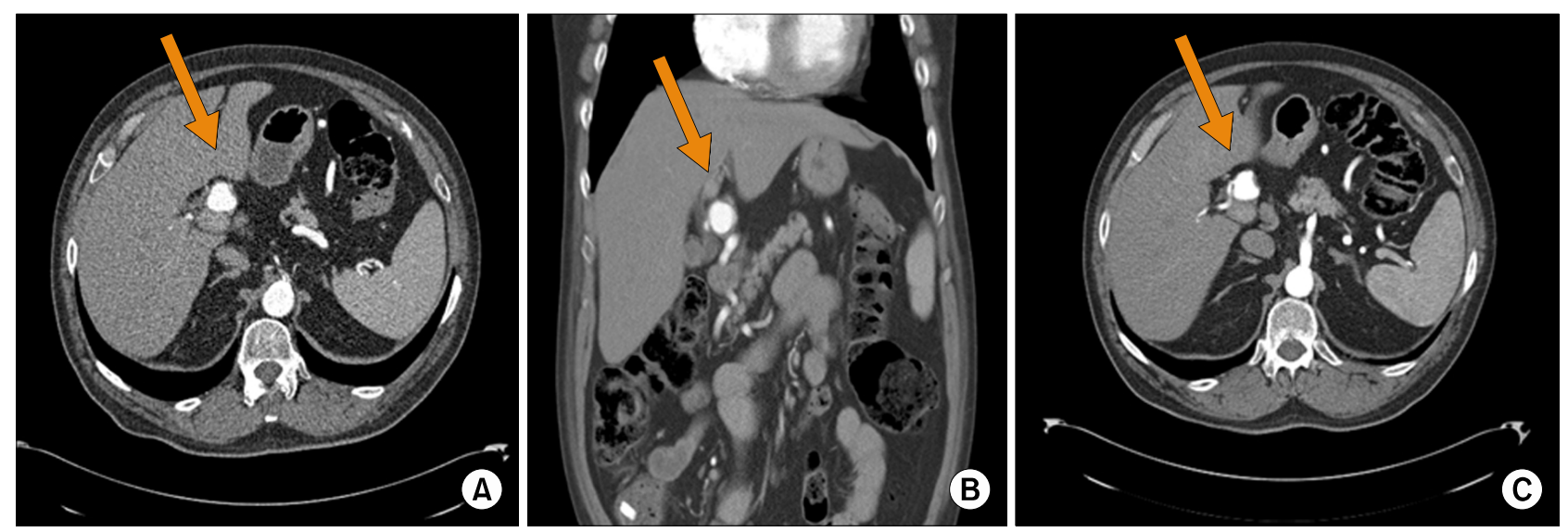

Fig. 2. Patient 2: (A-C) Stable hepatic artery aneurysm on imaging obtained 3 months apart.

years following the procedure (Fig. 1E).

Patient 2 was a 69-year-old man whose hepatic artery aneurysm was found incidentally on imaging obtained for evaluation of a hip pain. The aneurysm involved the bifurcation of the common hepatic arteries and both right and left hepatic arteries were arising directly from the aneurysm (Fig. 2). He also suffered from coronary artery and peripheral vascular diseases, and he had multiple prior surgeries including coronary artery bypass and aortic valve replacement, as well as bilateral common iliac stents. He was asymptomatic from his hepatic artery aneurysm, which at the time of diagnosis measured 2.6 $\mathrm{cm}$. Due to peripheral vascular disease, the patient was not a candidate for intravascular interventions, and he 
elected not to pursue aggressive operative management. The aneurysm was followed with a serial imaging spaced 3 months apart, and 3 consecutive studies did not reveal any changes.

Patient 3 was a 41-year-old man who presented with a sudden onset of severe abdominal pain. His past medical history was unremarkable with the exception of prolonged history of tobacco use. Subsequent imaging revealed a retroperitoneal hematoma in association with a $3-\mathrm{cm}$ hepatic artery aneurysm, as well as pedunculated mass arising from the right lobe of the liver (Fig. 3A, B). The aneurysm involved the main hepatic artery and extended from the gastroduodenal artery (GDA) origin to the bifurcation into the right and left hepatic arteries. The mass did not have radiological characteristics typical for liver cancer, and his tumor markers were within normal limits (CA-99 -11.4, alpha-fetoprotein-3.5, CEA-1.3).

The patient underwent exploratory laparotomy. His liver mass was resected first, and pathology was consistent with focal nodular hyperplasia. Then the attention was turned to the aneurysm. The aneurysm was completely excised, and pathology revealed fibrocalcific atherosclerosis.
The plan was to perform interposition graft with a saphenous vein, however an autologous vein was found to be too small. A cryopreserved cadaveric femoral vein was used for reconstruction instead. The graft was anastomosed to common hepatic artery at the GDA takeoff proximally and to the right and left hepatic arteries distally. Postoperatively the patency of the graft was confirmed with an arteriogram at three months and then with ultrasounds spaced 3 months apart (Fig. 3C). Twenty-two months after the initial operation the patient presented to an outside hospital with a massive gastrointestinal bleed. On imaging, the patient was found to have duodenohepatic arterioenteric fistula. The patient then underwent staged operations. First patient had a Viabahn ${ }^{\circledR}$ duodenal stent placement to minimize the enteric leak. During surgery it was noted that the aneurysm was fused to the first part of the duodenum. The previous cryopreserved femoral vein was friable and formed a phlegmon. As definitive surgery, the patient's left femoral vein was used as jump graft between aorta and hepatic artery. Postoperatively the patient is being followed with CTA for his repair which is stable (Fig. 3D).
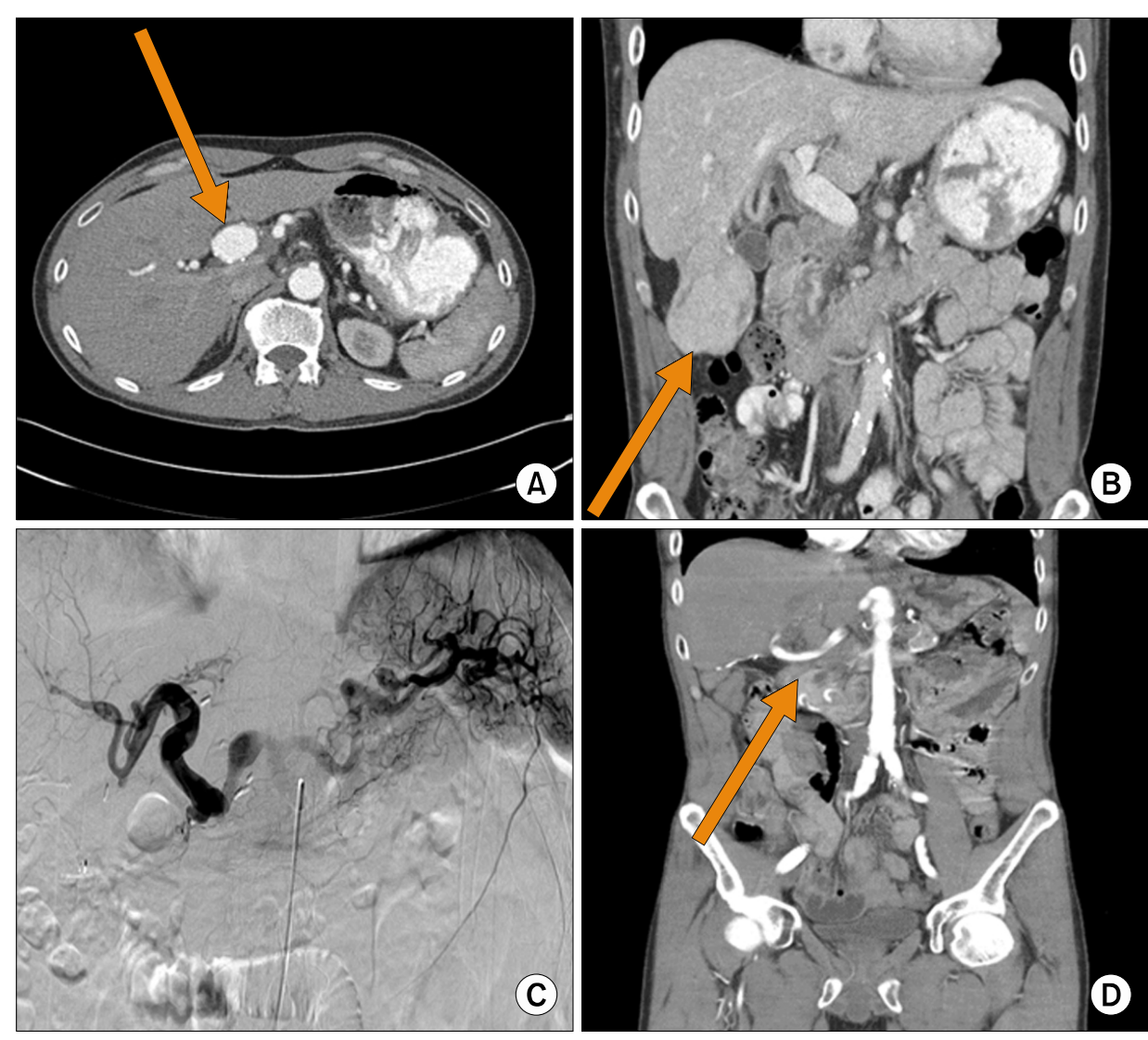

Fig. 3. Patient 3: (A) Hepatic artery aneurysm prior to surgery; (B) pedunculated mass arising from the right lobe of the liver; (C) post-surgical angiogram, demonstrating resolution of the aneurysm; (D) post second surgery CT angiogram, demonstrating iliac conduit. 
Patient 4 was a 56-year-old woman with a remote history of alcoholism who presented with jaundice, acholic stools and abdominal pain. Her diagnostic work-up revealed acute liver failure and a large hepatic artery aneurysm, causing compression of extrahepatic bile ducts (Fig. 4). The patient was taken to the operating room with a plan to perform exploratory laparotomy with intraoperative angiogram and stenting if possible. A large pulsatile aneurysm was found to involve a common hepatic artery. Intraoperative arteriogram revealed that the aneurysm was arising from the hepatic artery at the origin of gastroduodenal artery (GDA) and was believed to be a sequela of prior episodes of pancreatitis. It was determined that placing a stent across the aneurysm would likely lead to occlusion of the left hepatic artery, therefore a surgical approach with open bypass was chosen. The patient's splenic artery was found to be of adequate length to serve as a conduit. About $6 \mathrm{~cm}$ of splenic artery were dissected from its origin. Its distal end was then ligated, and the artery was moved over the hepatic hilum. The hepatic artery was then divided just proximal to its bifurcation and end to end anastomosis was performed between the splenic and proper hepatic artery. The remaining aneurysm was then decompressed and its outflow over sewn. The patient's biliary obstruction was managed with a biliary stent placed endoscopically. Post-procedure the patient elected to transfer her care to a different hospital and no follow-up imaging is available at this time.

\section{DISCUSSION}

Among visceral aneurysms, hepatic artery aneurysms are uncommon. They represent the second most common site for aneurysm in the splanchnic circulation following the splenic artery. Their pathophysiology is not completely understood and there are many risk factors which are described in literature most of which were present in our four patients (Table 2). Most commonly, they are believed to be caused by atherosclerosis, trauma, or be iatrogenic in nature. ${ }^{5}$ Hypertension has been documented as one of the most common comorbid conditions in patients with hepatic artery aneurysms. ${ }^{6}$ They are common in males $(2: 1)$, and most often present in their sixth decade of life. ${ }^{7}$ The exact incidences of hepatic artery aneurysms remain unknown. A retrospective study from the Mayo Clinic between 1980 and 1998 identified 36 patients with hepatic artery aneurysms, estimating the incidence at approximately $0.002 \%{ }^{8}$

The natural history of hepatic artery aneurysms is somewhat unclear. $\mathrm{Lu}$ et al. ${ }^{9}$ reported that there is no as-
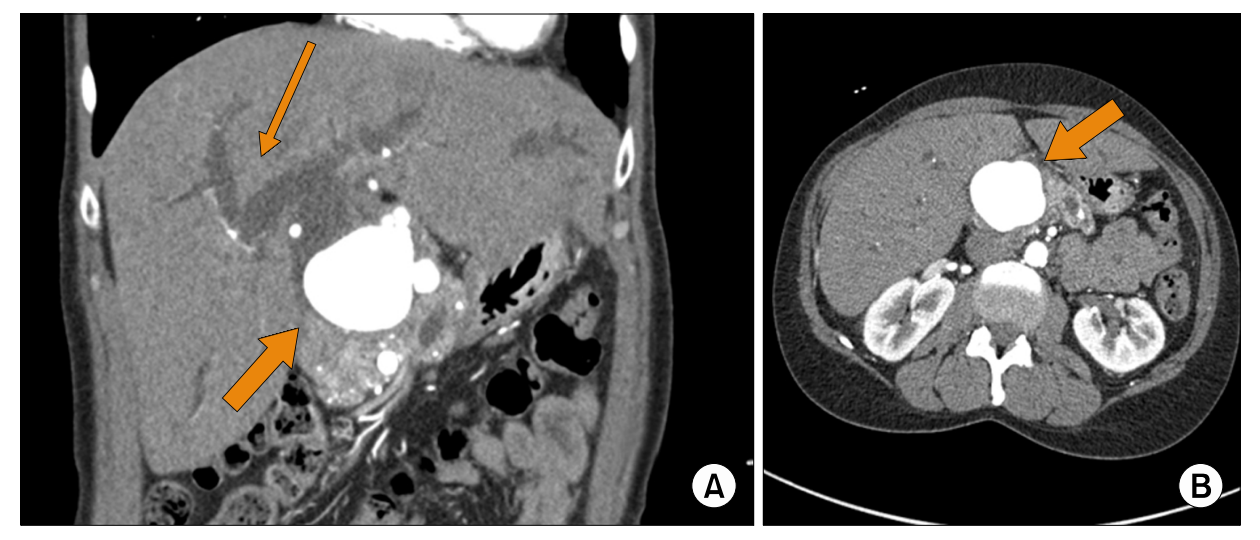

Fig. 4. Patient 4: Pre-operative imaging. (A) Coronal imaging with a thick arrow indicating the aneurysm, and a thin arrow showing intrahepatic biliary dilatation; (B) hepatic artery.

Table 2. Patient medical history

\begin{tabular}{|c|c|c|c|c|c|c|}
\hline Risk factor & Hypertension & Vascular disease & Pancreatitis & Diabetes & Tobacco use & $\begin{array}{c}\text { Autoimmune } \\
\text { disease }\end{array}$ \\
\hline Patient 1 & & $\mathrm{X}$ & & & & \\
\hline Patient 2 & $\mathrm{X}$ & $\mathrm{X}$ & & $\mathrm{X}$ & & \\
\hline Patient 3 & & $\mathrm{X}$ & & & $\mathrm{X}$ & \\
\hline Patient 4 & & & $\mathrm{X}$ & & $\mathrm{X}$ & \\
\hline
\end{tabular}

Various risk factors associated with presentation 
sociation between aneurysm size and rupture. While Abbas et al. ${ }^{8}$ reported that aneurysms smaller than $2 \mathrm{~cm}$ are unlikely to rupture and in asymptomatic patients they can be safely observed. Hepatic aneurysms have a rupture rate of $14 \%$ and mortality from rupture is $40 \%{ }^{8}$ Symptomatic patients often present with Quinke's triad which includes jaundice, biliary colic and gastrointestinal hemorrhage. ${ }^{6}$ Half of hepatic artery aneurysms rupture into the biliary tract leading to hemobilia or gastrointestinal hemorrhage, while the other half of ruptures present with signs and symptoms of intraperitoneal hemorrhage. ${ }^{10}$

There is upward trend in incidental diagnosis of hepatic artery aneurysms due to overall increased frequency of imaging for various other reasons. This has helped to reduce the risk of rupture and allow for elective treatment of the aneurysms, particularly in larger aneurysms. Once diagnosed, definitive imaging is essential to delineate the accurate anatomy and size of aneurysm. CT angiogram, MR angiogram as well as formal aortogram with celiac artery angiography has been described in literature. Usually an aortogram is done with intention to treat the lesions. It is important to examine other common sites of visceral aneurysm to exclude multiple pathologies. Arteriography can determine presence of additional aneurysms as well as evaluate collateral flow to the liver and allow to select the most appropriate approach to management. ${ }^{11}$

Various treatment options exist for hepatic artery aneurysms ranging from observation to surgical resection. Various surgeries which have been described previously as well as in our study include hepatic resection for large intrahepatic aneurysm, excision and use of arterial or venous jump graft, bypass with jump graft and ligation. The decision on the surgical strategy for repair depends on location, size and feasibility of interventional radiology approaches. Aneurysms involving common hepatic artery may be either embolized or ligated in the presence of adequate collateral circulation from GDA or right gastric artery. If collateral circulation is not sufficient, the aneurysmal artery needs to be reconstructed or partial hepatectomy might be required. Intrahepatic aneurysm, on the other hand, might be treated with endovascular techniques, either by stenting or embolization. ${ }^{12}$

In our cohort, two of the patients $(1,2)$ were diagnosed incidentally and were asymptomatic. Patient 1 was managed successfully with intravascular approach, due to fa- vorable anatomy. Patient 2 on the other hand, with his extensive systemic vasculopathy was not a candidate for intravascular intervention. Surgical intervention was not attempted due to the patient's reluctance as well as presence of multiple comorbidities. During a period of 1-year follow-up the patient remains asymptomatic and there is no radiological evidence of the aneurysm progression. Patient 3 was surgically repaired and developed a duodenohepatic fistula nearly two years postoperatively. Patient 4 was surgically repaired but transferred care therefore little is known about the long-term results.

The cause of the aneurysm might be attributed to vascular disease in 3 out of 4 patients: patient 1 had vascular disease and was undergoing dialysis for kidney failure, patient 2 who had a system wide involvement of his vasculature, and patient 3, who was a heavy smoker. One patient has multiple episodes of pancreatitis and chronic inflammation might have caused hepatic artery aneurysm as described previously in the literature. ${ }^{13}$

Due to relatively rare incidences of hepatic artery aneurysms, there are no clear guidelines on their management. In our case series we have shown that in selected high risk patients these lesions can be observed or if the anatomy is feasible these aneurysms can be treated using endovascular techniques. Surgical approach is reserved for patients who are high risk for rupture and carry high morbidity. Long term results of any of these interventions remain unknown.

\section{ORCID}

Ashley Rosenberg: https://orcid.org/0000-0002-9249-4778

Katarzyna Trebska-McGowan: https://orcid.org/0000-0001-8208-4815

Trevor Reichman: https://orcid.org/0000-0002-2303-1606 Amit Sharma: https://orcid.org/0000-0002-8784-5182

Adrian Cotterell: https://orcid.org/0000-0001-6479-0628

Brian Strife: https://orcid.org/0000-0003-0151-6538

Aamir A. Khan: https://orcid.org/0000-0002-5163-0147

Vinay Kumaran: https://orcid.org/0000-0003-0800-6290

David A. Bruno: https://orcid.org/0000-0002-6222-9228

Marlon F. Levy: https://orcid.org/0000-0002-3320-0493

Chandra Shekhar Bhati:

https://orcid.org/0000-0002-4333-5551 


\section{REFERENCES}

1. Chadha M, Ahuja C. Visceral artery aneurysms: diagnosis and percutaneous management. Semin Intervent Radiol 2009;26:196206.

2. Bacalbasa N, Brezean I, Anghel C, Barbu I, Pautov M, Balescu I, et al. Successful resection and vascular ligation of a large hepatic artery aneurysm-a case report and literature review. In Vivo 2017;31:979-982.

3. Røkke O, Søndenaa K, Amundsen S, Bjerke-Larssen T, Jensen D. The diagnosis and management of splanchnic artery aneurysms. Scand J Gastroenterol 1996;31:737-743.

4. Madhusudhan KS, Venkatesh HA, Gamanagatti S, Garg P, Srivastava DN. Interventional radiology in the management of visceral artery pseudoaneurysms: a review of techniques and embolic materials. Korean J Radiol 2016;17:351-363.

5. Dolapci M, Ersoz S, Kama NA. Hepatic artery aneurysm. Ann Vasc Surg 2003;17:214-216.

6. Berceli SA. Hepatic and splenic artery aneurysms. Semin Vasc Surg 2005;18:196-201.
7. Rapp JH, et al. Chapter 34: Arteries. In: Doherty GM. eds. CURRENT Diagnosis \& Treatment: Surgery, 13e. New York, NY: McGraw-Hill; 2010.

8. Abbas MA, Fowl RJ, Stone WM, Panneton JM, Oldenburg WA, Bower TC, et al. Hepatic artery aneurysm: factors that predict complications. J Vasc Surg 2003;38:41-45.

9. Lu M, Weiss C, Fishman EK, Johnson PT, Verde F. Review of visceral aneurysms and pseudoaneurysms. J Comput Assist Tomogr 2015;39:1-6.

10. Ricotta JJ, Akbari CM. Abdominal vascular emergencies. In: Zinner MJ, Ashley SW, ed. Maingot's abdominal operations. 12th ed. New York: McGraw Hill Professional, 2013:pp.000-000.

11. O’Driscoll D, Olliff SP, Olliff JF. Hepatic artery aneurysm. Br J Radiol 1999;72:1018-1025.

12. Jana M, Gamanagatti S, Mukund A, Paul S, Gupta P, Garg P, et al. Endovascular management in abdominal visceral arterial aneurysms: a pictorial essay. World J Radiol 2011;3:182-187.

13. Yu YH, Sohn JH, Kim TY, Jeong JY, Han DS, Jeon YC, et al. Hepatic artery pseudoaneurysm caused by acute idiopathic pancreatitis. World J Gastroenterol 2012;18:2291-2294. 